\title{
Knowledge and Risk Factors for Osteoporosis among Pre-elderly
}

\author{
Muhammad Ramdhani, ${ }^{1}$ Dicky Mulyadi, ${ }^{2}$ Nita Arisanti ${ }^{3}$ \\ ${ }^{1}$ Faculty of Medicine, Universitas Padjadjaran, ${ }^{2}$ Department of Orthopaedics and Traumatology, \\ Faculty of Medicine, Universitas Padjadjaran/Dr. Hasan Sadikin General Hospital Bandung, \\ ${ }^{3}$ Departement of Public Health, Faculty of Medicine, Universitas Padjadjaran
}

\begin{abstract}
Background: Osteoporosis is a disease characterized by abnormal loss of bone density resulting in bones that are brittle and liable to fracture. Most cases of fracture in the world are due to osteoporosis. In Indonesia, the prevalence of osteopenia (early osteoporosis) and of osteoporosis are relatively high. One of the causes of this situation is the low level of public knowledge about how to prevent osteoporosis. This study was conducted to identify the knowledge and risk of osteoporosis among pre-elderly at Cipacing Village Jatinangor District in 2014.

Methods: This descriptive study was conducted at Cipacing Village Jatinangor District to 160 respondents who were classified as pre-elderly (aged 45-59 years) and assessed on knowledge and risk factors for osteoporosis through questionnaire-guided interviews after the informed consent was obtained.The collected data were presented using frequency distribution.

Results: A total of 100 respondents (62.5\%) had good knowledge about osteoporosis-related information, including definitions, causes, risk factors, signs and symptoms, impacts, and prevention. Most respondents, 79 respondents $(49.4 \%)$, are at risk for osteoporosis.

Conclusions: Knowledge of osteoporosis among pre-elderly at Cipacing Village Jatinangor District are largely classified into "good knowledge" category. [AMJ.2015;2(4):608-14]
\end{abstract}

Keywords: Knowledge, osteoporosis, pre-elderly, risk

\section{Introduction}

Osteoporosis is a disease which is characterized by reduced bone mass and increased bone fragility and the bone turned to be easily fractured. ${ }^{1}$ In 2005, the Nutrition Development and Research Center of the Department of Health, Republic of Indonesia collected data about the risk of osteoporosis using a sample of 65.727 people in sixteen regions in Indonesia (including West Java) by using the Bone Mass Density (BMD) examination as the method and the clinical bone sonometer as diagnostic tool, and found the prevalence of osteopenia (early osteoporosis) was $41.7 \%$ and of osteoporosis was $10.3 \%$ respectively. This evidently showed that two out of five of the Indonesian population, are at risk of osteoporosis. ${ }^{2,3}$

This high risk of osteoporosis in Indonesia is caused by the increasing life expectancy of Indonesian population, which in 2005 reached 67.68 years. Unfortunately, the public knowledge about how to prevent osteoporosis is still low. This was proven by the low intake of calcium among Indonesian population. ${ }^{2}$ In 2012, from the data of population based on age group in Jatinangor District, it was found that Cipacing Village had the biggest number of population aged 40 years and older as many as 2,617 people. From interviews with the Puskesmas (Public Health Center) staff in Jatinangor District, it was also known that data about risk of osteoporosis in thecommunity was not recorded because the bone mass density screening tool was not available. Therefore, this study was conducted to assess the knowledge and risk of osteoporosis among pre-elderly at Cipacing Village, Jatinangor District in 2014.

\section{Methods}

This study was a descriptive method, conducted at Cipacing Village, Jatinangor

Correspondence: Muhammad Ramdhani, Faculty of Medicine, Universitas Padjadjaran, Jalan Raya Bandung-Sumedang Km.21, Jatinangor, Sumedang, Indonesia, Phone: +62 85379679900 Email: ramdhani210294@gmail.com 
District, from September to October 2014. All the questions in the questionnaire which were delivered to the respondents in this study had been approved by the Health Research Ethics Committee Faculty of Medicine Universitas Padjdadjaran.

The population of this study was people who lived at Cipacing Village Jatinangor District. The inclusion criteria of this study were people who lived at Cipacing Village who pertained to the pre-elderly (aged 45-59 years) and were willing to be respondents. The exclusion criteria of this study were respondents who filled in the questionnaire incorrectly or incompletely. Furthermore, the sample size in this quantitative study was calculated using the formula of sample size calculation in a descriptive categorical study. Next, the samples were selected by using the simple random sampling technique. Then, from the 18 Rukun Warga (RW) in Cipacing Village, the number of samples of each RW was determined by calculating the proportion. The proportion of each RW was calculated by multiplying the number of pre-elderly population in the RW with the minimum amount of sample (150 respondents) and then the result was divided by the total of pre-elderly population in Cipacing Village $(2,794$ people). From the calculation of the proportion, the number of samples was known to be 160 respondents.

The primary data of this study, including the demographic characteristics of the respondents, knowledge, and the risk of osteoporosis, was obtained through a questionnaire-guided interview method. In this study, there were two questionnaires, one was about "Knowledge of Osteoporosis (questionnaire I)" and the other was about "One Minute Test of Osteoporosis Risk (questionnaire II)". Questionnaire I which consisted of 10 questions with Guttman scale (True or False) was associated with knowledge of osteoporosis: definitions, causes, risk factors, signs and symptoms, effects, and prevention. A value of 1 was given for each correct answer and 0 for each wrong answer so that the highest value was 10 and the lowest value was 0 . In this study, the cut-off point was used to categorize the respondents' knowledge. Since the data distribution of the total knowledge score was not normal, the cut-off point of 7 was obtained from the value of the median total score of all respondents. Good level of knowledge was if the total score obtained by the respondent was $\geq 7$, while poor level of knowledge was if the total score obtained by the respondent was $<7$. This questionnaire was a modification taken from a previous study, which has been considered to meet the criteria of validity, while the reliability test was performed in this study. ${ }^{4}$

Questionnaire II which consisted of ten questions with Guttman scale (Yes or No) was associated with the risk of osteoporosis: family history, history of fractures, corticosteroid treatment, decrease in height, alcohol consumption and smoking, history of diarrhea and gastrointestinal diseases, premature menopause and menstruation disorders (for female respondents), and impotence or decreased of libido (for male respondents). The questionnaire was developed by the International Osteoporosis Foundation (IOF) and has been translated into Indonesian language by the Ministry of Health Republic of Indonesia.2 Based on the IOF, respondent who answered "Yes" on at least one of the questions, belong to at risk for osteoporosis category, while respondent who answered "No" to all questions, belong to not at risk for osteoporosis category. The questionnaire was considered to meet the criteria of validity and reliability.

Furthermore, the collected data was processed by computer using the Microsoft Excel and statistical software. The data analysis, scoring, until the determination of the category was performed by using the Microsoft Excel. The frequency and percentage of respondents who belonged to each group of variables based on the category was then calculated. The calculation of the frequency and percentage of respondents who went to each group of variables were calculated and analyzed by using statistical software. The results of this study data was presented in tabular form.

\section{Results}

This study was conducted in March-November 2014. The data collection was performed from 11to30 September 2014 in 18 RWs in Cipacing Village, Jatinangor District. The study involved 160 respondents who were classified as preelderly (aged 45-59 years old).

Table 1 shows the distribution of respondents' characteristics involved in this study. Variables in the table were age, sex, education, and occupation. The respondents' age ranged from 45 years to 59 years (Table 1 ). The mean, median, and mode were not on the same number, which showed that the age data in this study were not normally distributed. 
Table 1 Demographic Characteristics of Respondents

\begin{tabular}{|c|c|c|c|}
\hline & Characteristics & Frequency (n) & Percentage (\%) \\
\hline \multicolumn{4}{|l|}{ Age } \\
\hline Mean & $=50,93$ years old & & \\
\hline Median & $=50,5$ years old & & \\
\hline Mode & $=45$ years old & & \\
\hline Range & $=45-59$ years old & & \\
\hline SD & $=4,55$ & & \\
\hline \multicolumn{4}{|l|}{ Gender } \\
\hline Male & & 25 & 15.6 \\
\hline Female & & 135 & 84.4 \\
\hline \multicolumn{4}{|c|}{ Education } \\
\hline None & & 3 & 1.9 \\
\hline Element & y school & 66 & 41.3 \\
\hline Junior hi & h school & 43 & 26.9 \\
\hline Senior $\mathrm{h}$ & h school & 42 & 26.3 \\
\hline Diploma & D1/D2/D3) & 1 & 0.6 \\
\hline Undergr & duate /S2/S3 & 5 & 3.1 \\
\hline \multicolumn{4}{|c|}{ Occupation } \\
\hline Not emp & yed & 124 & 77.5 \\
\hline Housew & & 116 & 72.5 \\
\hline Employe & & 36 & 22.5 \\
\hline Police & & 1 & 0.6 \\
\hline Security & uard & 1 & 0.6 \\
\hline Civil em & oyee & 2 & 1.3 \\
\hline Farmer & & 4 & 2.5 \\
\hline Teacher & & 4 & 2.5 \\
\hline Entrepre & eur & 24 & 15 \\
\hline
\end{tabular}

Therefore, the average age was using the median value, i.e. 50.5 years. Most common age of the respondents was 45 years.

The table also shows that the respondents were dominated by female with the percentage $84.4 \%$, while male respondent were only $15.6 \%$. Most of the respondents' education level was elementary school, with a total of 66 respondents (41.3\%). Three respondents who were not in school (1.9\%) showed the education level for pre-elderly at Cipacing Village was not evenly distributed.

The majority of female respondents were housewives $(72.5 \%)$, so the percentage of unemployed respondents became large $(77.5 \%)$. Also, most of the respondents were entrepreneur (15\%).

One hundred respondents (62.5\%) had a good knowledge of osteoporosis-related information, including definitions, causes, risk factors, signs and symptoms, effects, and prevention (Table 2). However, a total of 60 respondents $(37.5 \%)$ respondents had poor knowledge of osteoporosis-related information.

From the distribution of respondents' 
Table 2 Category of Knowledge and Risk for Osteoporosis

\begin{tabular}{|c|c|c|}
\hline Category & Frequency (n) & Percentage (\%) \\
\hline \multicolumn{3}{|l|}{ Knowledge } \\
\hline Good & 100 & 62.5 \\
\hline Poor & 60 & 37.5 \\
\hline \multicolumn{3}{|l|}{ Risk } \\
\hline At risk & 79 & 49.4 \\
\hline Not at risk & 81 & 50.6 \\
\hline
\end{tabular}

knowledge questionnaire, more than $80 \%$ of respondents understood well the definition, causes, and effects of osteoporosis. However, the majority of respondents still believed that women and men had the same risk of osteoporosis, which in fact is women are more at risk of osteoporosis, especially those who have entered the menopausal stage. This could be seen since only 33 respondents $(20.6 \%)$ were able to answer correctly to this question. In contrast, more than $80 \%$ of respondents knew that long term immobility affected the high risk of osteoporosis. Seventy respondents $(43.8 \%)$ knew that the sudden pain felt when bending is one of the symptoms of osteoporosis. Related to the prevention of osteoporosis, 149 respondents (93.1\%) knew that the morning sun was a good source of vitamin $\mathrm{D}$ that was good for bone density. A total of 105 respondents (65.6\%) knew that simple exercises such as brisk walking, running, and rope jumping can help maintain bone density. However, only 55 respondents $(34.4 \%)$ were aware that the source of calcium was not only milk. The majority of respondents still assumed that calcium can only be obtained by consuming milk.

Table 2 shows that almost half of the respondents were at risk for osteoporosis, with a total of 79 respondents (49.4\%).

Table 3 shows 26 respondents $(16.3 \%)$ had parents who were diagnosed with osteoporosis or had hip fractures due to falls or minor collision, either the father or the mother. In addition, 11 respondents $(6.9 \%)$ claimed to have suffered fractures due to falls or minor

Table 3 Distribution of Respondents' Answer on Risk for Osteoporosis Variables

\begin{tabular}{|c|c|c|c|}
\hline \multirow{2}{*}{\multicolumn{2}{|c|}{ Question }} & \multicolumn{2}{|c|}{ Answer "Yes" } \\
\hline & & $\begin{array}{l}\text { Frequency } \\
\text { (n) }\end{array}$ & $\begin{array}{l}\text { Percentage } \\
\quad(\%)\end{array}$ \\
\hline 1. & $\begin{array}{l}\text { Parents have been diagnosed with osteoporosis or have a hip } \\
\text { fracture due to a relatively mild fall or collision }\end{array}$ & 26 & 16.3 \\
\hline 2. & Had fracture due to a relatively mild fall or collision & 11 & 6.9 \\
\hline 3. & $\begin{array}{l}\text { Had been taking corticosteroids medication (cortisone, } \\
\text { prednisone, etc.) for more than three months }\end{array}$ & 9 & 5.6 \\
\hline 4. & Height has reduced by more than $3 \mathrm{~cm}$ & 18 & 11.3 \\
\hline 5. & Drinking alcohol regularly (beer, palm wine, whiskey, etc.) & 2 & 1.3 \\
\hline 6. & Smoking more than 20 cigarettes a day & 9 & 5.6 \\
\hline 7. & Often suffering from diarrhea (e.g. gastrointestinal diseases) & 17 & 10.6 \\
\hline 8. & Have menopause before the age of 45 years (for female respondent) & 18 & 13.3 \\
\hline 9. & $\begin{array}{l}\text { Menstruation has stopped (amenorrhea) for } 12 \text { months or more, } \\
\text { except for pregnancy or menopause (for female respondent) }\end{array}$ & 9 & 6.7 \\
\hline 10. & $\begin{array}{l}\text { Has experienced having impotence, decreased libido or other } \\
\text { symptoms related to low testosterone levels (for male respondent) }\end{array}$ & 8 & 32 \\
\hline
\end{tabular}


collision. Out of 160 respondents, nine $(5.6 \%)$ admitted to taking corticosteroid drugs within a period of more than three months, where as it is known that the use of corticosteroid medications for a long time can affect bone density. This can occur due to the purchase of corticosteroid drugs without a prescription. On the other hand, 18 respondents $(11.3 \%)$ felt their height had reduced $3 \mathrm{~cm}$ from the previous heights. These 18 respondents felt their posture became slightly bent.

Drinking alcohol and smoking are unhealthy habits that can accelerate bone density loss.1 From the Table above, it shows that two respondents $(1.3 \%)$ drank alcohol regularly and nine respondents $(5.6 \%)$ smoked more than twenty cigarettes per day. Furthermore, gastrointestinal diseases also can be one of the risks of osteoporosis. 5 In this study, 17 respondents $(10.6 \%)$ often had diarrhea. Out of 135 female respondents in this study, 18 respondents $(13.3 \%)$ experienced menopause before the age of 45 years and nine $(6.7 \%)$ had experienced menstruation stops (amenorrhea) for 12 months or more, which were not due to pregnancy or menopause. Out of 25 male respondents, eight (32\%) of them claimed to have a decreased libido or often called impotence.

\section{Discussion}

The results showed that from 160 pre-elderly people at Cipacing Village, Jatinangor District who were respondents of this study, 100 people $(62.5 \%)$ had good knowledge related to osteoporosis, including definitions, causes, risk factors, prevention, and impact. Furthermore, based on the education, most respondents with higher education level (senior high school, diploma, and undergraduate) had good knowledge of osteoporosis. According to Notoatmodjo ${ }^{6}$, people with higher formal education have a higher knowledge level than those with lower formal education, because they are considered to be more capable to understand easily the meaning and importance of health and health care utilization. However, respondents with low educational level (none, elementary, and secondary) mostly were able to answer questions properly, hence they were also classified into good knowledge category. This finding indicates that knowledge is not only influenced by formal education, but can also be influenced by various information sources, such as family, print media, electronic media, and others.

A cross-sectional study conducted in
Isfahan, Iran, stated that respondents with higher education levels have significantly better knowledge related to osteoporosis when compares to respondents with lower education levels. ${ }^{7}$ In addition, knowledge of osteoporosisrelated study has also been performed on the nursing profession in Singapore, and it concluded that the knowledge of nurses is still considered insufficient, especially in relation to the prevention and management of osteoporosis. ${ }^{8}$ Meanwhile, Endicott et al., showed that after the intervention in the form of specific education about osteoporosis to respondents, the respondents' knowledge of osteoporosis has increased very significantly. ${ }^{9}$

Although $62.5 \%$ of respondents had good knowledge of osteoporosis, there were several untrue answers to some questions in the knowledge questionnaire. More than $70 \%$ of respondents believed that women and men had the same risk for osteoporosis, whereas the appropriate literature states that women are at greater risk for osteoporosis, especially after menopause. A total of 90 respondents found that pain occurring when bending the body was not a symptom of osteoporosis, but a symptom of arthritis. Additionally, back pain due to spinal deformity, decreased mobility of the body, decreased of appetite due to abdominal pressure could be signs and symptoms of osteoporosis, where there has been a compression fracture of the spine. ${ }^{2}$ In addition to the signs and symptoms, most respondents still assumed that calcium could only be obtained by consuming milk.

The recommended daily intake of calcium is $1,200 \mathrm{mg}$ and in fact, in addition to milk, calcium can also be obtained from other food ingredients: fish, vegetables (such as spinach, cabbage, and broccoli), beans, and cereal., ${ }^{2,10}$ Over the past 20 years, at least 14 randomized clinical trials (RCTs) were conducted in various countries to determine the effects of vitamin $\mathrm{D}$ with or without calcium on the incidence of fractures. Four of them have shown a significant reduction of the incidence of fractures, two are in the borderline, and eight other studies have found no significant effect. ${ }^{11}$ On the other hand, a Canadian study showed that calcium intake to $1,000 \mathrm{mg}$ per day has a significant association with a decrease in the mortality rate in women statistically, although the results are inconclusive for calcium intake in excess of $1,000 \mathrm{mg}$ per day. ${ }^{12}$

Based on Table 2, a total of 79 respondents $(49.4 \%)$ had an increased risk for osteoporosis. Out of the total of respondents which were included in the at risk group, 26 respondents 
(16.3\%) had parents who have been diagnosed with a bone less density or have experienced a hip fracture due to collision or a relatively mild fall. Furthermore, family history of osteoporosis is one of the risk factors and an estimated $80 \%$ genetically inherited bone density subsequently, it can be interpreted that osteoporosis can be lowered. ${ }^{1,2}$ Based on a study in the United States, it concluded that a family history of osteoporosis is a significant and independent risk factor for osteoporosis in women aged 35 years and older ${ }^{13}$ Another research in theUnited States conducted by Meadows et al. ${ }^{14}$, discovers that out of the 1.800 women who have undergone treatment for osteoporosis, about half have reported a family history of osteoporosis.

On the other hand, 18 respondents $(11.3 \%)$ felt their height has reduced by $3 \mathrm{~cm}$ from the previous conditions. In their study, CunhaHenriques et al. ${ }^{15}$, showed that the clinical characteristics height of postmenopausal women with osteoporosis are shorter than those without osteoporosis. Out of 135 female respondents in this study, 18 people (13.3\%) experienced menopause before the age of 45 years. Moreover, a population-based observational study in Sweden, which was conducted on 390 white European women, concluded that early menopause is a significant risk factor for osteoporosis, related to hormonal changes.$^{16}$ Additionally, a cross-sectional study in China, also found the result that women who experienced early menopause have a significant risk of osteoporosis compared to women who experienced menopause at the age of 50 years. ${ }^{17}$ Table 5 shows that $79.7 \%$ of respondents were classified as at risk were women. Meanwhile, from a cohort study in four US regions, it was obtained that $10 \%$ of women with moderate osteopenia, change into osteoporosis within five years and $10 \%$ of women with severe osteopenia change into osteoporosis within a year. ${ }^{18}$

On the other hand, Burke-Doe et al. ${ }^{19}$, conducted a research related to the risk for osteoporosis by using the Osteoporosis SelfAssessment Tool (OST), where the calculation of the risk index is obtained based on age and weight of the respondent The respondents will be grouped into "High Risk "," Moderate risk ", or "Low risk ". Out of 49 respondents, aged $78-98$ years, $60.9 \%$ of them have a high risk for osteoporosis. ${ }^{19}$ However, the Osteoporosis Self-Assessment Tool (OST) is considered to have a moderate sensitivity and low specificity for use in men. ${ }^{20}$

In this study, there were limitations that may affect the implementation of thestudy results since it has not conducted a search of the factors that affect the respondents' knowledge of osteoporosis. Sampling was carried out during working hours consequently, not all pre-elderly in Cipacing Village had a chance to be selected as respondents. The large area of Cipacing Village, led to the uneven sampling in each RW (neighborhood).

This study concluded that the knowledge of osteoporosis in pre-elderly in Cipacing Village, Jatinangor District are largely classified into "good knowledge" category, with a total of 100 respondents $(62.5 \%)$ and 79 respondents $(49.4 \%)$ are classified into "at risk" category for osteoporosis.

Further studies are therefore necessary to determine the relationship between knowledge and the risk of osteoporosis, the correlation between knowledge and the prevalence of osteoporosis, and others. Although most respondents have good knowledge related to osteoporosis, there are still pre-elderly in Cipacing Village Jatinangor District who has poor knowledge related to osteoporosis, hence it is advisable for health institutions to provide education about osteoporosis to the community at Jatinangor District. This study also recommends health institutions to provide the Puskesmas at Jatinangor District with a bone mass density examination tool, so examination of bone mass density at Jatinangor District can be performed periodically to determine the exact risk for osteoporosis in Jatinangor District community.

\section{References}

1. Solomon L, Warwick D, Nayagam S, editors. Apley's system of orthopaedics and fractures. 9th ed. London: Hodder Arnold; 2010.

2. Menteri Kesehatan Republik Indonesia. Pedoman pengendalian osteoporosis. Jakarta: Kementerian Kesehatan RI; 2008.

3. Jahari AB, Prihatini S. Risiko osteoporosis di Indonesia. Gizi Indon. 2007;30(1):1-11.

4. Damayanti AP. Gambaran tingkat pengetahuan osteoporosis pada pegawai administrasi perempuan di Universitas Indonesia tahun 2012 [minor thesis]. Depok: Universitas Indonesia; 2012.

5. Katz S, Weinerman S. Osteoporosis and gastrointestinal disease. Gastroenterol Hepatol. 2010;6(8):506-17.

6. Notoatmodjo S. Promosi kesehatan dan ilmu perilaku. Jakarta: PT Rineka Cipta; 2007. 
7. Etemadifar MR, Nourian SM, FereidanEsfahani M, Shemshaki H, Nourbakhsh M, Zarezadeh A. Relationship of knowledge about osteoporosis with education level and life habits. World J Orthop. 2013; 4(3):139-43.

8. Zhang RF, Chandran M. Knowledge of osteoporosis and its related risk factors among nursing professionals. Singapore Med J. 2011;52(3):158-62.

9. Endicott RD. Knowledge, health beliefs, and self-efficacy regarding osteoporosis in perimenopausal women. J Osteoporos. 2013;2013:1-6.

10. Setyohadi B, Hutagalung EU, Adam JMF, Suryaatmadja M, Budiparama NC, Jatim SANM, et al. Summary of Indonesian guidelines for diagnosis and management of osteoporosis. JAFES. 2014;27(2):14750.

11. Lips P, Bouillon R, Van Schoor NM, Vanderschueren D, Verschueren S, Kuchuk $\mathrm{N}$, et al. Review article: Reducing fracture risk with calcium and vitamin D. Clin Endocrinol. 2010;73(3):277-85.

12. Langsetmo L, Berger C, Kreiger N, Kovacs CS, Hanley DA, Jamal SA, et al. Calcium and vitamin D intake and mortality: results from the Canadian multicentre osteoporosis study (CaMos). J Clin Endocrinol Metab. 2013;98(7):3010-8.

13. Robitaille J, Yoon PW, Moore CA, Liu T, Irizarry-Delacruz $\mathrm{M}$, Looker $\mathrm{AC}$, et al. Prevalence, family history, and prevention of reported osteoporosis in U.S. women. Am J Prev Med. 2008;35(1):47-54.

14. Meadows E, Mitchell B, Bolge S, Johnston
J, Col N. Factors associated with treatment of women with osteoporosis or osteopenia from a national survey. BMC Womens Health. 2012;12(1):1-9.

15. Cunha-Henriques S, Costa-Paiva L, PintoNeto AM, Fonsechi-Carvesan G, Nanni L, Morais SS. Postmenopausal women with osteoporosis and musculoskeletal status: a comparative cross-sectional study. J Clin Med Res. 2011;3(4):168-76.

16. Svejme O, Ahlborg HG, Nilsson JÅ, Karlsson MK. Early menopause and risk of osteoporosis, fracture and mortality: a 34-year prospective observational study in 390 women. BJOG. 2012;119(7):810-6.

17. Qiu C, Chen H, Wen J, Pengli Zhu, Fenghui Lin, Baoying Huang, et al. Associations between age at menarche and menopause with cardiovascular disease, diabetes, and osteoporosis in Chinese women. J Clin Endocrinol Metab. 2013;98(4):1612-21.

18. Gourlay ML, Fine JP, Preisser JS, May RC, Li C, Lui L-Y, et al. Bone-density testing interval and transition to osteoporosis in older women. N Engl J Med. 2012;366(3):22533.

19. Burke-Doe A, Hudson A, Werth H, Riordan DG. Knowledge of osteoporosis risk factors and prevalence of risk factors for osteoporosis, falls and fracture in functionally independent older adults. J Geriatr Phys Ther. 2008;31(1):11-7.

20. Richards JS, Lazzari AA, Teves Qualler DA, Desale S, Howard R, Kerr GS. Validation of the osteoporosis self-assessment tool in US male veterans. J Clin Densitom. 2013;17(1):32-7. 